\title{
Standardization of thyroid fine needle aspiration procedure and outcomes within an endocrine surgery department
}

\author{
Mustafa Donmez ${ }^{1}$, Husnu Aydin ${ }^{1}$, Emin Kose ${ }^{1}$, Bora Kahramangil' ${ }^{2}$, Ozgun Erten ${ }^{1}$, Mehmet Gokceimam ${ }^{1}$, \\ Serkan Akbulut ${ }^{1}$, Judy Jin ${ }^{1}$, Vikram Krishnamurthy ${ }^{1}$, Joyce Shin ${ }^{1}$, Allan Siperstein ${ }^{1}$, Eren Berber ${ }^{1}$ \\ ${ }^{1}$ Department of Endocrine Surgery, Cleveland Clinic, Cleveland, OH, USA; ${ }^{2}$ Department of General Surgery, Cleveland Clinic Florida, Weston, \\ FL, USA \\ Contributions: (I) Conception and design: M Donmez, H Aydin, E Kose, B Kahramangil, O Erten, M Gokceimam, S Akbulut, E Berber; (II) \\ Administrative support: M Donmez, E Berber, J Jin, V Krishnamurthy, J Shin, A Siperstein; (III) Provision of study materials or patients: E Berber, \\ J Jin, V Krishnamurthy, J Shin, A Siperstein; (IV) Collection and assembly of data: M Donmez, H Aydin, E Kose, B Kahramangil, O Erten, M \\ Gokceimam, S Akbulut; (V) Data analysis and interpretation: All authors; (VI) Manuscript writing: All authors; (VII) Final approval of manuscript: \\ All authors. \\ Correspondence to: Eren Berber, MD. 9500 Euclid Avenue Cleveland, OH 44195, USA. Email: berbere@ccf.org.
}

\begin{abstract}
Background: Fine needle aspiration (FNA) biopsy is an essential procedure for thyroid nodules. Although, the efficacy of surgeon-performed thyroid FNA biopsies has been demonstrated in the literature, there are insufficient data regarding how to establish an efficient program with a low insufficiency rate within a group practice.

Methods: An endocrine surgery thyroid FNA biopsy program was established in 2000 by one surgeon, with training of additional partners during fellowship and upon recruitment. The results within 18 years were analyzed. The FNA biopsies were performed by endocrine surgeons under ultrasound guidance without onsite pathologist review.

Results: A total of 5,469 FNA biopsies were performed by 7 surgeons. The total number of FNA biopsies performed by each surgeon varied between 291-1,378. FNA biopsies were performed in 2 passes using 22 -gauge needles under constant suction. The overall insufficiency rate was $4.3 \%$, with individual surgeon rates ranging between $2.7 \%$ and $7.2 \%$. The insufficiency rate for the whole team ranged between $3.3 \%$ and $5 \%$ when examined in 5 -year blocks.
\end{abstract}

Conclusions: This study shows that an establishment of a highly efficient thyroid FNA biopsy program within a group practice is possible with a structured endocrine surgical training and adoption of a standard technique.

Keywords: Thyroid; fine needle biopsy; endocrine surgeon; technique

Submitted Jul 26, 2020. Accepted for publication Dec 13, 2020.

doi: $10.21037 /$ gs-20-630

View this article at: http://dx.doi.org/10.21037/gs-20-630

\section{Introduction}

Thyroid nodules are detected in up to $70 \%$ of the patients undergoing a neck ultrasound (1-3). Fine needle aspiration (FNA) biopsy is an essential procedure to rule out malignancy, which is present in $5-10 \%(4-6)$. The performance of thyroid FNAs by endocrine surgeons is a new concept, but simplifies otherwise a multidisciplinary process and facilitates triage to surgery if required $(4,7,8)$. As a result, these patient benefits have been recognized and various surgical series with an adequate sampling rate, ranging between $92-100 \%$, have been reported in the literature (4,8-12). Previous studies have focused on a comparison of surgeon versus radiologist-performed thyroid FNA in regards to adequacy $(6,8)$, the impact of trainees on sufficiency rates (13-15) and the effect of an on- 


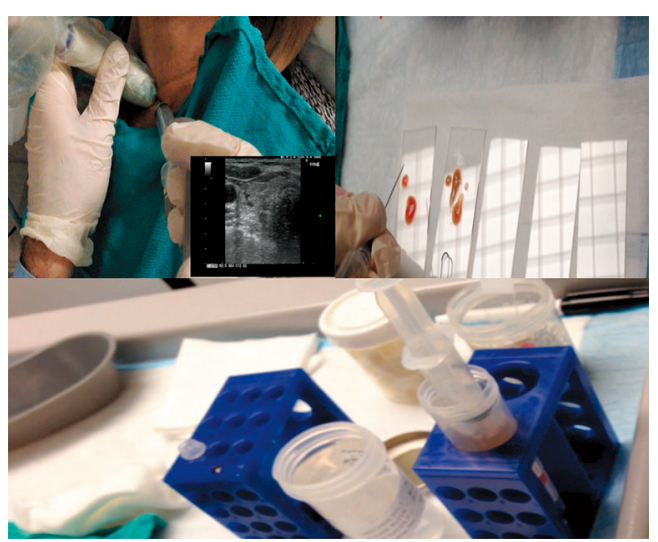

Figure 1 Demonstration of the fine needle aspiration (FNA) technique used in the study. Under ultrasound guidance, by inserting the needle in plane of the transducer, the nodules were biopsied in 2 passes. Then the aspirates were laid on a total of 4 slides and also washed in a CytoLyt solution. An onsite cytopathologist review was not performed.

site cytopathologist to avoid insufficient biopsies $(11,16,17)$.

In modern medical practice, departments have to function as a unit, with standardization of skills and outcomes. The challenges of departmental units include the fact that a learning curve is involved with invasive procedures and that the group includes surgeons at various stages in their careers, and hence with different skill levels. With increasing institutional and patient expectations for standardized and consistent outcomes, it is important to streamline a high-volume procedure, such as thyroid FNAs within group practices.

To our knowledge, the performance analysis of a group, rather than individuals, has not been performed for thyroid FNAs. This is a complex dynamic task, as it requires setting up a certain benchmark goal, anticipation of failures related to the learning curve of individuals and utilization of a feedback circuit that should involve a continuous quality measurement and perfection of the group performance in a progressive fashion. Our group has been a pioneer in surgeon-performed ultrasound in endocrine surgery for the past 20 years. The aim of this study is to analyze the experience and process for standardization of surgeon-performed thyroid FNAs within this group practice.

We present the following article in accordance with the STROBE reporting checklist (available at http://dx.doi. org/10.21037/gs-20-630).

\section{Methods}

The study was conducted in accordance with the Declaration of Helsinki (as revised in 2013). The study was approved by institutional/regional/national ethics/ committee/ethics board of Cleveland Clinic (IRB\# 18041) and individual consent for this retrospective analysis was waived. An endocrine surgery thyroid FNA program was established in 2000 by one surgeon (AS). A target of less than $10 \%$ insufficiency rate was set as a goal. Upon determination that the senior surgeon's insufficiency rate was less than $10 \%$, this technique was then taught to additional junior partners during their endocrine surgery fellowship at the program or upon recruitment from other training programs. Outcomes were periodically reviewed for each surgeon, to ensure achievement of the $<10 \%$ insufficiency goal, as part of a continuous quality improvement process. The insufficiency rates were communicated back to each surgeon as a quality metric. The results of this practice within 18 years were analyzed from an IRB-approved departmental database.

The decision for thyroid FNA was made based on the American Thyroid Association 2009 and 2015 guidelines on the management of thyroid nodules $(18,19)$. The FNAs were performed by individual endocrine surgeons under ultrasound and without on-site pathologic review. The patients were positioned on the exam table in a semi Fowler position, with the neck extended and the head and torso raised to 30 degrees. After the nodules were recognized on ultrasound and patients consented for FNA, a $10-\mathrm{mm}$ syringe with a 22 -gauge needle were used to biopsy the nodules under ultrasound guidance and continuous application of suction using a pistol. About 10 thrusts were made with the needle for each pass and pressure applied to the skin after biopsy. Two passes were performed for each nodule. The aspirates were sprayed on a total of 4 slides, smears created and fixated in alcohol. The residual aspirate from each syringe was also washed in a CytoLyt solution and sent for cytology (Figure 1). To eliminate confusion in interpreting the results, cystic nodules were excluded, with only solid nodules analyzed in the study.

As it is known that there could be inter-observer differences in the evaluation of thyroid nodules between cytopathologists (20), the FNA slides were reviewed and decided upon by a group of cytopathologists and not by an individual cytopathologist. 
Table 1 The number of total biopsies performed versus insufficient samples reported on cytopathology per individual surgeons in the study

\begin{tabular}{lccc}
\hline Surgeon & Number of biopsies performed & Number of insufficient biopsies & Rate of insufficiency (\%) \\
\hline Senior & 783 & 21 & 2.68 \\
Surgeon \#1 & 1,378 & 56 & 4.06 \\
Surgeon \#2 & 291 & 21 & 7.21 \\
Surgeon \#3 & 928 & 54 & 5.81 \\
Surgeon \#4 & 1,304 & 45 & 3.45 \\
Surgeon \#5 & 482 & 27 & 5.60 \\
Surgeon \#6 & 303 & 12 & 3.96 \\
Total & 5,469 & 236 & 4.31 \\
\hline
\end{tabular}

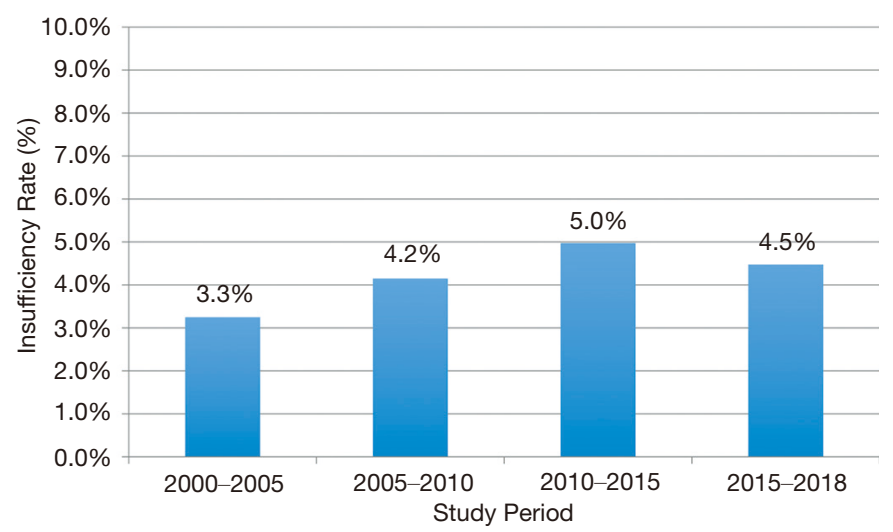

Figure 2 Bar graphs showing the insufficiency rate of the whole group divided into 5 -year periods.

\section{Statistical analysis}

The data were obtained from an IRB-approved database. Statistics were performed using descriptive analysis with JMP Version 13.1 (SAS Institute, Inc, Cary, NC).

\section{Results}

A total of 5469 FNAs performed by 7 endocrine surgeons. The number of FNAs performed by each surgeon varied between $291-1,378$. The overall insufficiency rate was $4.3 \%$, with individual surgeon rates ranging between $2.7 \%$ and $7.2 \%$ (Table 1). Over the course of the study, the insufficiency rate ranged between $3.3 \%$ and $5 \%$ when examined in 5-year blocks for the whole team (Figure 2). A typical learning curve was not observed for most surgeons, suggesting that this task was mastered in fellowship training (Figure 3). For one surgeon who was trained upon recruitment, an insufficiency rate of $12 \%$ in the first 100 FNAs dropped to $6 \%$ in the second 100 FNAs, suggesting a learning curve of 100 FNAs to optimize sufficiency above $90 \%$.

All biopsies were performed using 2 passes applying continuous suction with 22 -gauge needles. Complications included bleeding into 2 nodules in 2 patients. None of these patients required blood transfusions or emergency surgery.

\section{Discussion}

To our knowledge, this is the first study that evaluates a group practice to see if thyroid FNAs could be standardized to consistently achieve a target sufficiency rate by both the whole group and each member. Our results show that a technique that yields satisfactory outcomes can be mastered by a team and sustainable performance metrics be accomplished. A prerequisite for this model to be successful is a continuous periodic assessment of performance by 

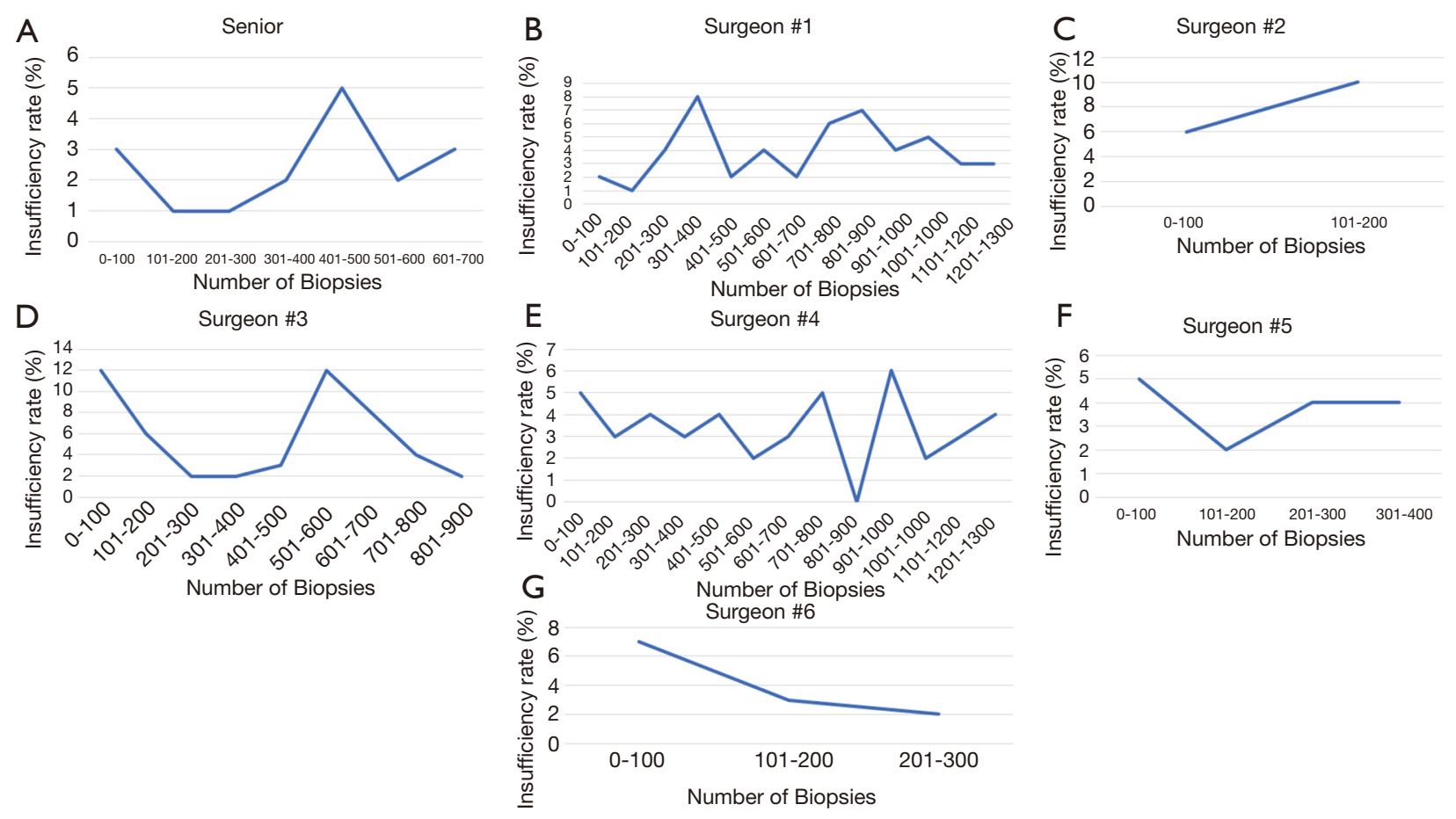

Figure 3 Line graphs showing the insufficiency rate for each surgeon, analyzed in 100 FNA-blocks.

using pre-determined metrics (sufficiency rate of $>90 \%$ ) and provision of regular feedback to individual surgeons about their performance. This standardization enabled the maintenance of $\geq 95 \%$ overall sufficiency rate for the whole group when examined in 5 -year blocks. We believe that this proficiency-based performance model could be applied to other interventional procedures in a group practice and would be analogous to evidence-based practice to optimize outcomes.

Upon increasing surgeon experience with ultrasound, opportunities to increase efficiency of patient care in the management of thyroid nodules have been recognized. Many studies have confirmed the efficacy of surgeonperformed thyroid nodule FNA $(3,4,6,8,10,14,15)$. Our recent study has further suggested the benefits of this practice to the assessment of lymph nodes (9). Although traditionally performed by radiologists, thyroid FNA has been successfully acquired by surgeons. A number of studies have confirmed an equivalency of the results when compared with those of radiologists $(6,7,21)$. In a study performed by Al-Azawi et al. (8), the inadequacy rate of thyroid FNAs done by radiologists versus surgeons was $9.3 \%$ and $5.3 \%$, respectively.

There is disagreement in the literature regarding the optimal technique for performing thyroid FNAs (11,16,17,22-26). Needle sizes that have been advocated range between 22 and 27 gauges in various reports $(11,13,16,24,26-29)$. There is also controversy regarding whether suction should be applied or not during the procedure $(22,24,26)$. Furthermore, whether a cytopathologist should be on site or not is another topic of controversy $(11,16,23)$. Finally, the number of passes and slides are also controversial (7,13-15,17,23,29-33). What these controversies suggest, as a bottom line, is that there are many techniques that could yield a high sufficiency for thyroid FNAs. In our study, 2 passes with $22-\mathrm{G}$ needles using constant suction under ultrasound guidance without an on-site cytopathology achieved a low insufficiency rate that could be reproduced within a group practice in a consistent and sustainable fashion. We suggest other groups to employ the same operational process for an evidencebased standardization of a given technique. However, the individual members should be ready to modify their technique based on regular feedback about target metrics.

An interesting finding of our study was that a typical pattern of learning curve was not demonstrated when results of each surgeon were analyzed chronologically. We believe that this is related to two factors. First, the skill can be mastered during fellowship training. The insufficiency rate 
of the majority of surgeons was $<10 \%$ in the first 100 FNAs in the current study. For one surgeon who was trained upon recruitment, 100 FNAs was necessary for the learning curve to achieve insufficiency rate below $10 \%$. Hence, we suggest the routine incorporation of thyroid FNAs, along with surgical ultrasound, to endocrine surgical fellowship programs. Second, we speculate that with accumulating experience, more challenging nodules (i.e., smaller, deeply located, etc.) are targeted by individual surgeons, which lead to a horizontal sufficiency rate over time. Our findings contrast with those showed by two studies $(13,15)$ that reported improved sufficiency rates with increasing experience.

In summary, this report shows that an establishment of a highly efficient thyroid FNA program for a surgical group practice is possible with a structured endocrine surgical training and adoption of a standard technique. The maintenance of efficiency requires a periodic quality review of outcomes and acquisition of a standard FNA technique with known acceptable outcomes. The most appropriate management of thyroid nodules regarding organizational set up (i.e., FNAs performed by endocrinologists, radiologists, pathologists versus surgeons) is beyond the scope of this paper.

\section{Acknowledgments}

This study was presented as a poster in 88th Annual Meeting of the American Thyroid Association in October 3-7, 2018 in Washington, DC.

Funding: None.

\section{Footnote}

Reporting Checklist: The authors have completed the STROBE reporting checklist. Available at http://dx.doi. org/10.21037/gs-20-630

Data Sharing Statement: Available at http://dx.doi. org/10.21037/gs-20-630

Peer Review File: Available at http://dx.doi.org/10.21037/gs20-630

Conflicts of Interest: All authors have completed the ICMJE uniform disclosure form (available at http://dx.doi. org/10.21037/gs-20-630). EB serves as an unpaid editorial board member of Gland Surgery from Aug 2020 to Jul 2022.
The authors have no conflicts of interest to declare.

Ethical Statement: The authors are accountable for all aspects of the work in ensuring that questions related to the accuracy or integrity of any part of the work are appropriately investigated and resolved. The study was conducted in accordance with the Declaration of Helsinki (as revised in 2013). The study was approved by institutional/ regional/national ethics/committee/ethics board of Cleveland Clinic (IRB\# 18-041) and individual consent for this retrospective analysis was waived.

Open Access Statement: This is an Open Access article distributed in accordance with the Creative Commons Attribution-NonCommercial-NoDerivs 4.0 International License (CC BY-NC-ND 4.0), which permits the noncommercial replication and distribution of the article with the strict proviso that no changes or edits are made and the original work is properly cited (including links to both the formal publication through the relevant DOI and the license). See: https://creativecommons.org/licenses/by-nc-nd/4.0/.

\section{References}

1. Isaac A, Jeffery CC, Seikaly H, et al. Predictors of nondiagnostic cytology in surgeon-performed ultrasound guided fine needle aspiration of thyroid nodules. J Otolaryngol Head Neck Surg 2014;43:48.

2. Singh Ospina N, Brito JP, Maraka S, et al. Diagnostic accuracy of ultrasound-guided fine needle aspiration biopsy for thyroid malignancy: systematic review and meta-analysis. Endocrine 2016;53:651-61.

3. Hambleton C, Kandil E. Appropriate and accurate diagnosis of thyroid nodules: a review of thyroid fineneedle aspiration. Int J Clin Exp Med 2013;6:413-22.

4. Bohacek L, Milas M, Mitchell J, et al. Diagnostic Accuracy of Surgeon-Performed Ultrasound-Guided FineNeedle Aspiration of Thyroid Nodules. Ann Surg Oncol 2012;19:45-51.

5. Coorough N, Hudak K, Jaume JC, et al. Nondiagnostic fine-needle aspirations of the thyroid: is the risk of malignancy higher? J Surg Res 2013;184:746-50.

6. Bozkurt H, İrkörücü O, Aziret M, et al. Comparison of 1869 thyroid ultrasound guided fine needle aspiration biopsies between general surgeons and interventional radiologists. Ann Med Surg (Lond) 2016;10:92-102 .

7. Gu WX, Tan CS, Ho TW. Surgeon-Performed Ultrasound-Guided Fine-Needle Aspiration Cytology 
(SP-US-FNAC) Shortens Time for Diagnosis of Thyroid Nodules. Ann Acad Med Singap 2014;43:320-4.

8. Al-azawi D, Mann GB, Judson RT, et al. Endocrine Surgeon-Performed US Guided Thyroid FNAC is Accurate and Efficient. World J Surg 2012;36:1947-52.

9. Kahramangil B, Kose E, Donmez M, et al. Efficacy of surgeon performed, ultrasound-guided lymph node fine needle aspiration in patients with thyroid pathologic conditions. Surgery 2018;164:657-64.

10. Bhatki AM, Brewer B, Robinson-Smith T, et al. Adequacy of surgeon-performed ultrasound-guided thyroid fine needle aspiration biopsy. Otolaryngol Head Neck Surg 2008;139:27-31.

11. Witt RL, Sukumar VR, Gerges F. Surgeon-Performed Ultrasound-Guided FNAC With On-Site Cytopathology Improves Adequacy and Accuracy. Laryngoscope 2015;125:1633-6.

12. Karadeniz Cakmak G, Emre AU, Tascilar O, et al. Diagnostic Adequacy of Surgeon-Performed UltrasoundGuided Fine Needle Aspiration Biopsy of Thyroid Nodules. J Surg Oncol 2013;107:206-10.

13. De Fiori E, Rampinelli C, Turco F, et al. Role of operator experience in ultrasound-guided fine-needle aspiration biopsy of the thyroid. Radiol Med 2010;115:612-8.

14. Fernandes VT, Magarey MJ, Kamdar DP, et al. Surgeon performed ultrasound-guided fine-needle aspirates of the thyroid: 1067 biopsies and learning curve in a teaching center. Head Neck 2016;38 Suppl 1:E1281-4.

15. Fernandes VT, De Santis RJ, Enepekides DJ, et al. Surgeon-performed ultrasound guided fine-needle aspirate biopsy with report of learning curve; a consecutive caseseries study. J Otolaryngol Head Neck Surg 2015;44:42.

16. O'Malley ME, Weir MM, Hahn PF, et al. US-guided Fine-Needle Aspiration Biopsy of Thyroid Nodules: Adequacy of Cytologic Material and Procedure Time with and without Immediate Cytologic Analysis. Radiology 2002;222:383-7.

17. Sidiropoulos N, Dumont LJ, Golding AC, et al. Quality Improvement by Standardization of Procurement and Processing of Thyroid Fine-Needle Aspirates in the Absence of On-site Cytological Evaluation. Thyroid 2009; 19:1049-52.

18. Cooper DS, Doherty GM, Haugen BR, et al. Revised American Thyroid Association Management Guidelines for Patients with Thyroid Nodules and Differentiated Thyroid Cancer. Thyroid 2009;19:1167-214.

19. Haugen BR, Alexander EK, Bible KC, et al. 2015 American Thyroid Association Management Guidelines for
Adult Patients with Thyroid Nodules and Differentiated Thyroid Cancer. Thyroid 2016;26:1-133.

20. Ronen O, Cohen H, Sela E, et al. Differences in cythopathologist thyroid nodule malignancy rate. Cytopathology 2020;31:315-20.

21. Graciano AJ, Fischer CA, Chone CT, et al. Efficacy of ultrasound-guided fine-needle aspiration performed by surgeons newly trained in thyroid ultrasound. Head Neck 2017;39:439-42.

22. Kim DW. How to do it: ultrasound-guided fine-needle aspiration of thyroid nodules that commonly result in inappropriate cytology. Clin Imaging 2013;37:1-7.

23. Naïm C, Karam R, Eddé D. Ultrasound-Guided FineNeedle Aspiration Biopsy of the Thyroid: Methods to Decrease the Rate of Unsatisfactory Biopsies in the Absence of an On-site Pathologist. Can Assoc Radiol J 2013;64:220-5.

24. Kim MJ, Kim EK, Park SI, et al. US-guided Fine-Needle Aspiration of Thyroid Nodules: Indications, Techniques, Results. Radiographics 2008;28:1869-86.

25. Kaliszewski K, Zubkiewicz-Kucharska A, Wojtczak B, et al. Ultrasound Guided Fine-Needle Aspiration Biopsy of Thyroid Nodules: Does Radiologist Assistance Decrease the Rate of Unsatisfactory Biopsies? Adv Clin Exp Med 2016;25:93-100.

26. Degirmenci B, Haktanir A, Albayrak R, et al. Sonographically guided fine-needle biopsy of thyroid nodules: the effects of nodule characteristics, sampling technique, and needle size on the adequacy of cytological material. Clin Radiol 2007;62:798-803.

27. Robitschek J, Straub M, Wirtz E, et al. Diagnostic efficacy of surgeon-performed ultrasound-guided fine needle aspiration: A randomized controlled trial. Otolaryngol Head Neck Surg 2010;142:306-9.

28. Rafael OC, Klein M, Serbonich MM, et al. Young Investigator Challenge: Building an Ultrasound-Guided FNA Clinic-Our 5-Year Experience: From Project to Practice. Cancer Cytopathol 2017;125:161-8.

29. Kelly NP, Lim JC, DeJong S, et al. Specimen Adequacy and Diagnostic Specificity of Ultrasound-Guided Fine Needle Aspirations of Nonpalpable Thyroid Nodules. Diagn Cytopathol 2006;34:188-90.

30. Lieu D. Cytopathologist-Performed Ultrasound-Guided Fine-Needle Aspiration and Core-Needle Biopsy: A Prospective Study of 500 Consecutive Cases. Diagn Cytopathol 2008;36:317-24.

31. Lee YJ, Kim DW, Jung SJ. Comparison of sample adequacy, pain-scale ratings, and complications associated 
with ultrasound-guided fine-needle aspiration of thyroid nodules between two radiologists with different levels of experience. Endocrine 2013;44:696-701.

32. Moon HJ, Kwak JY, Kim EK, et al. Ultrasonographic characteristics predictive of non diagnostic results for fine- needle aspiration biopsies of thyroid nodules. Ultrasound Med Biol 2011;37:549-55.

33. Ahmeti I, Simonovska L, Krstevska B, et al. Fine Needle Aspiration in Thyroid Nodules - One Year Experience. Open Access Maced J Med Sci 2015;3:307-9.

Cite this article as: Donmez M, Aydin H, Kose E, Kahramangil B, Erten O, Gokceimam M, Akbulut S, Jin J, Krishnamurthy V, Shin J, Siperstein A, Berber E. Standardization of thyroid fine needle aspiration procedure and outcomes within an endocrine surgery department. Gland Surg 2021;10(2):567-573. doi: 10.21037/gs-20-630 